\title{
Analysis on the Scenes of Water Lilies and Portrait of a Lady on Fire
}

\author{
Jiayi Shi ${ }^{1, *}$ \\ ${ }^{1}$ Hangzhou Foreign Language School, Hangzhou, Zhejiang, China, 310000, \\ *Corresponding author. Email:shunotfound@163.com
}

\begin{abstract}
Céline Scimma, the French independent filmmaker, is a highly acclaimed and renowned director. The sexual fluidity of females is a typical motif of her films. However, when most of the discussions about Sciamma's movies focus on the theme, her felicitous application of settings is simply neglected. Setting is prominent for the integrity of a film's expression but the significance of setting is always underrated by audience. By investigating Sciamma's the two lesbian films Water Lilies and Portrait of a Lady on Fire, from the four dimensions of setting which is proposed by Robert McKee, the analysis demonstrates how the setting functions in a film to achieve the story and convey director ' $s$ notion. It shows that the utilization of setting helps to improve the dramatic tension and to construct a fuller character image through setting up their relationship with the space of story.
\end{abstract}

Keywords: film, scene, Water Lilies, Portrait of a Lady on Fire

\section{INTRODUCTION}

Undoubtedly, Céline Scimma is an outstanding French director of the new generation. With only four feature films, she breaks the stereotype and makes a difference to the industry. Her debut film, Water Lilies, premiered in Cannes in 2007 and it was selected for screening in the section Un Certain Regard. Four years later, Sciamma carried out Tomboy. Girlhood, released in 2014 and selected to be screened as part of the Directors' Fortnight section of the Cannes Film Festival. The latest feature film Portrait of a Lady on Fire, won the award of Queer Palm and Best Screenplay at the 2019 Cannes Film Festival. Subverting heteronormativity is the most common theme in Sciamma's movies[1]. She tries to express a new imaginary of eroticism and build a dialogue of love based on equality, without gender domination[2].

Céline Scimma is always praised for the "female perspective", however, apart from the discussion of director's own identity, her excellent adoption of distinctive settings to achieve the completion of the films and displays her personal narrative features are usually ignored. As the theory of Robert McKee states, setting is four-dimensional--- it consists of period, duration, location, and level of conflict[3]. The employment of setting is especially notable in two lesbian films of Sciamma. Therefore, a further interpretation on Water Lilies and Portrait of a Lady on Fire will be presented in this study to observe the function and the importance of settings. This may straightforwardly reflects how the presence of settings contribute to the film and how the director utilizes settings to express her thoughts.

\section{ADOLESCENT GIRLS IN SWIMMING POOL AND CHANGING ROOM}

Water Lilies illustrates the sexual awakening of three teenage girls. The protagonist Marie, meets Floriane, the captain of synchronized swim team, by chance and she gradually becomes infatuated with her. Meanwhile Marie's best friend, Anne, who is still possessive of Marie, has a crush on Floriane's boyfriend. Céline Sciamma connects this story with hazy relationship in a summer break - the film starts by the summer and also ends before the summer. The time choice provides those adolescent girls a specific and personal period to be mature, or pretend to be mature. 


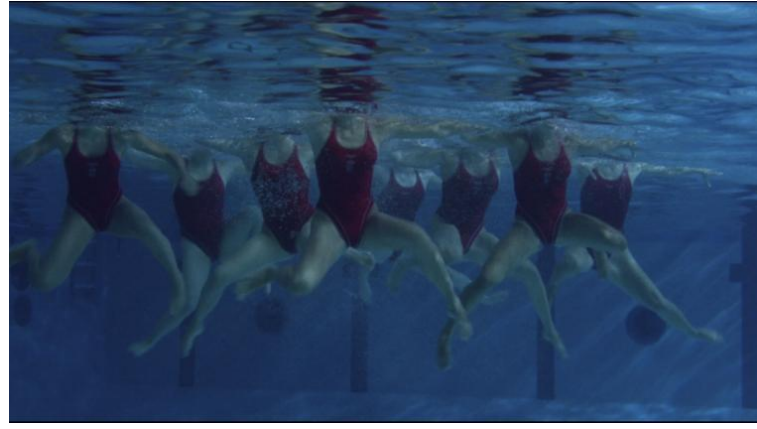

Figure 1. The scene of girls in swimming pool in Water Lilies

Without the tedious rules of campus life, young girls with excess hormones grasp the chance to explore what arousal is and try to become an adult. Besides, only when the denouement comes earlier than backing to the dull routine in school, what has happened in summer can remains a hallucination.

Swimming pool is apparently the most significant scene throughout the Water Lilies as shown in Figure 1. The film opens with the brilliant performance of school synchronized swim team in the swimming pool and that is where Marie's obsession for Floriane starts. Later in the movie, Marie was invited by Floriane to watch the training of her team. She saw their elegant movement above the water and then she dived down into pools finding out that these beautiful girls who were showing off their blossoming adolescence had to constantly make unaesthetic kicking under the water. Figure.1 presents this underwater scene of girls. In this case, the concept of swimming pool can be associated with the original French name of Water Lilies, Naissance des Pieuvres, which can be literally translated as "the birth of octopuses". According to Sciamma's review on Critikat, octopuses remind her of jealousy and desire. This monster-like thing will suck on the stomach and it is exactly the physical expression of the sentiment. The octopus is also an underwater animal, which is very soft and elegant in the water, but it is ridiculous when it comes to shore. This image perfectly fits the teenagers and Floriane will be a great example there. She seems like a classical character in teen dramas--- charming, having mature appearance and also showing feminity under the male gaze. However, Floriane is actually an inexperienced one who always trying to hide her immatureness and struggle beneath the glamorous surface.

Other than that, the female's locker room is also a scene that worth mentioning. No one is able to hide her body in this space, so it is certainly the best place to present the same-sex bodies. Marie, for instance, shows her figure anxiety and her heterosexual desire in the locker room. When she was wearing her swimsuit, her overcautious act exposes the uneasiness.

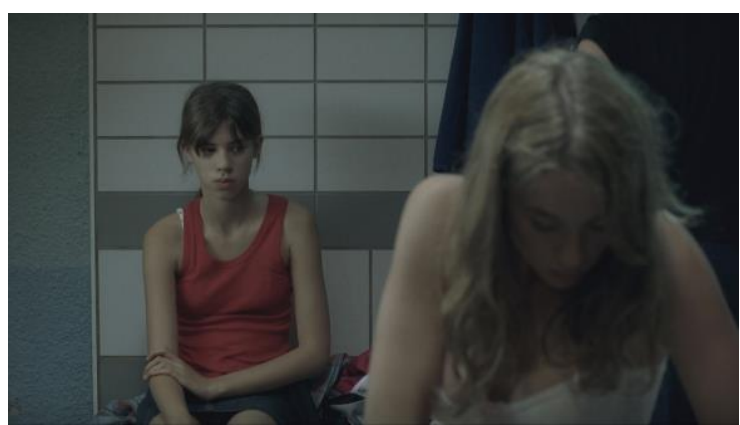

Figure2. The scene of Marie and Floriane in locker room in Water Lilies

Figure. 2 presents the reaction of Marie in the locker room. Everyone's figure is explicitly shown in the changing room and it is apparent that Marie feels like her slim body looks so undeveloped. Mary's eyes lingered unstoppably on Floriane, not only because of Floriane's good figure, but also because Floriane had the characteristics that Mary imagined that a mature woman should have. This is an inevitable, naturally occurring sexual attraction. Therefore, the environment of the dressing room puts a lot of pressure on the plot.

\section{LOVERS ON THE ISLAND}

Taking place at the end of 18th century, the film Portrait of a Lady on Fire depicts a romantic lesbian story. The female painter Marianne was hired to paint a portrait for a young lady named Héloïse, the daughter of a French countess, on a isolated island. The two women developed a forbidden affair but they eventually parted away because of Heloise's marriage[7]. The choice of time setting, which basically means that many default restraint will be set to the characters, is mesmerizing and special since everyone will expect how can a homosexual relationship between females appear in a society full of stale ideas. Audience are informed in the first fifteen minutes that Héloïse will marry a Milanese man she has never met after the portrait is complete. As a result, no matter how intense the love will be in the future, lovers will ultimately have to leave each other in the tears. The limited time duration of the story leads to the aesthetic of regret and deficiency, to some extent.

The major story of the Portrait of a Lady on Fire is takes place on an isolated island. The island scene is a proper symbol of a women community and it provides a vacuum environment for females. At the beginning of the film, Marianne, the artist whose career prospect is restricted simply because of gender, passes through the sea and the windy beach to land on the island. 


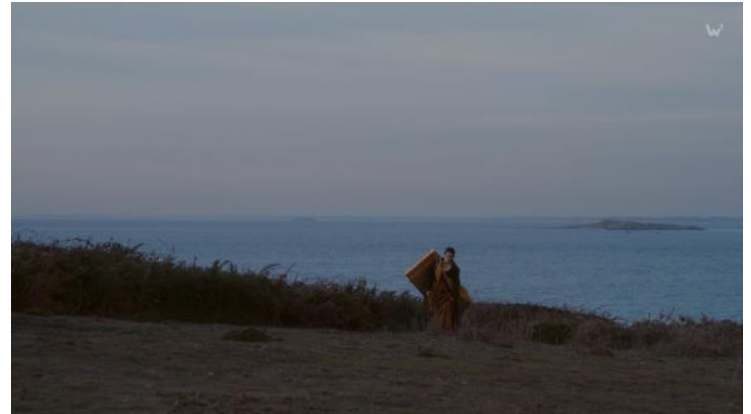

Figure3. The scene of the isolated island in Portrait of a Lady on Fire

Figure. 3 presents the background environment of this story. This can be explained as a temporary escape from the patriarchy after experiencing millions of difficulties brought by male-dominant society. It is not hard to realize that all the characters there are women---two protagonists and a maid, Sophie. The three of them use their force collectively to counter the invisible pressure exerted by the advocates of patriarchy[8]. During Sophie's abortion, Marianne and Héloïse never reprimand her but accompany patiently. This surgery is portrayed by Marianne as the coexistence of birth and death. The metaphor return the choice of reproduction to women. Women are free to build relationship across class, and are also free to choose to give birth or give up on life[9]. The scene of island thus combines with the strength of women to construct a specific female context in this movie.

Another crucial scene is the painting room of Marianne inside the old house they live, where the theme of gaze is introduced. The first portrait of Héloïse Marianne drew in this room was painted by the secret observation under the male gaze so she destroys it. Although Marianne's view of Héloïse initially began with the necessity of the painter's profession, as their subtle relationship develops, the situation in painting room varied. Héloïse started to sit in front of the Marianne for her to paint. Figure. 4 presents how the two women gaze each other in a narrative of equality at the scene of painting room. When Marianne watched the slight movements of Héloïse, Héloïse was also observing the tiny reactions of Marianne. They are like mirror images, seeing each other's every breath. The new portrait is created by the tender female gaze and the mutual lovers' gaze[10]. Héloïse is no longer the subject of the painting but the object of love and desire.

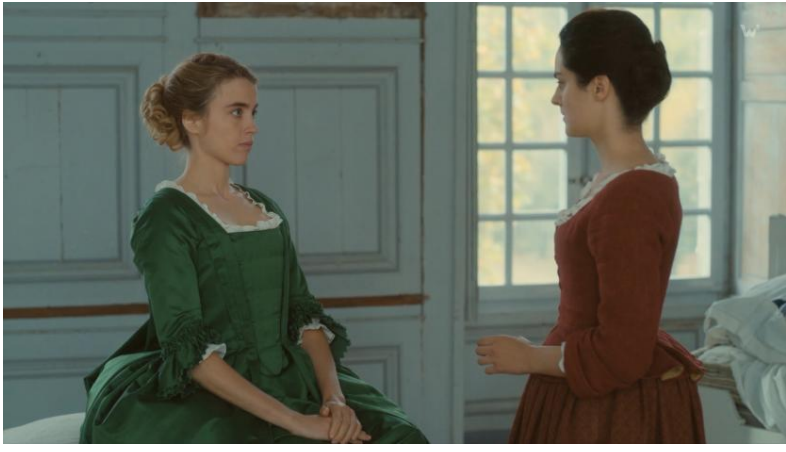

Figure4. The scene of women gazing each other in painting room in Portrait of a Lady on Fire

\section{CONCLUSION}

The setting of a film tend not to look prominent, however, it plays a vital role in a movie's integrity and it can make a great deal of contribution to the overall effect[11]. Setting is both a container for the character's behaviors and a participant in the narrative of the plot, which creates a special emotional atmosphere and spatial environment[12]. This paper explores the settings in Céline Scimma's films, helps audience to recognize the applications of settings in practical studies and grasp a more proficient understanding of the director. The analysis indicates that the setting generally serves two functions: to intensify the dramatic effects and to set up the relationship between characters themselves and the outside world. In brief, setting is essential for a film to complete the story and shape the characters[13].

\section{AUTHORS' CONTRIBUTIONS}

This paper is independently completed by the author.

\section{ACKNOWLEDGMENTS}

First and foremost, I would like to express my sincere gratitude to my professor for the valuable and systematical suggestions with kindness. He greatly improved my understanding of film analysis and provided a lot of useful materials. Also, his comment helped me to set a clear direction of the paper. Secondly, I extremely appreciate the help from my tutors. Without the meticulous guidance and patient encouragement, the completion of thesis could not be accomplished.

\section{REFERENCES}

[1] Bradbury-Rance, Clara. Where There' s Smoke: Seeing Sex in Portrait of a Lady on Fire. 2020.

[2] Garcia, M., \& Sciamma, C. Deconstructing the Filmmaker's Gaze: An Interview with Céline Sciamma. Cinéaste, 2019, 45(1), 8-11. 
[3] Fox A. Hearing the Crackles in the Background: Listening and Female Intimacy in 'Portrait of $a$ Lady on Fire', published on the film blog, 'Screen Queens'. 2020.

[4] Rong Rong. Multimodal stylistic interpretation of film scenes. Shandong Foreign Language Teaching, 2015,36(4): 15-24.

[5] Dai Degang. Scene:A method for quantitative analysis of film narrative[J]. Film Art, 2010(03): 110-115.

[6] Wang Yiting. Metaphors and symbols of suspense film scene space design[D]. Southwest Jiaotong University, 2015.

[7] Fox, A. Hearing the Crackles in the Background: Listening and Female Intimacy in 'Portrait of $a$ Lady on Fire'. Screen Queens. 2020.

[8] Xu Xing, Sun Jinghua. The aesthetics of camera narrative in Portrait of a Lady on Fire. Film Literature, 2020(14): 127-129.

[9] Song Rui, Yuan Yifan. Metaphor and Gaze in Portrait of a Lady on Fire[J]. Audiovisual,2020(12):83-85.

[10] Chen Baiyi. Portrait of a Lady on Fire: From the Male Gaze to the Identity Gaze. Drama and Film Review, 2020(3): 77-85.

[11] Xing Xianghu. Moving-viewing-seeing-in: an analysis of film scene maturation based on iconographic theory. Film Art,2018(4): 142-146

[12] Boggs, J. M. (1996). The art of watching films. Mayfield Publishing Company, 1280 Villa Street, Mountain View, CA 94041.

[13] Ma Qiang. On the aesthetic style of film scene design[J]. Film Literature,2011(17): 24-25. 